This item was submitted to Loughborough's Research Repository by the author.

Items in Figshare are protected by copyright, with all rights reserved, unless otherwise indicated.

\title{
A statistical summary of mall-based stair-climbing interventions
}

PLEASE CITE THE PUBLISHED VERSION

http://journals.humankinetics.com/jpah-back-issues/jpah-volume-8-issue-4-may/a-statistical-summary-of-mallbased-stair-climbing-interventions

\section{PUBLISHER}

(c) Human Kinetics, Inc.

\section{VERSION}

VoR (Version of Record)

LICENCE

CC BY-NC-ND 4.0

REPOSITORY RECORD

Webb, Oliver J., Frank F. Eves, and Jacqueline Kerr. 2019. "A Statistical Summary of Mall-based Stairclimbing Interventions". figshare. https://hdl.handle.net/2134/8924. 
This item was submitted to Loughborough's Institutional Repository (https://dspace.lboro.ac.uk/) by the author and is made available under the following Creative Commons Licence conditions.

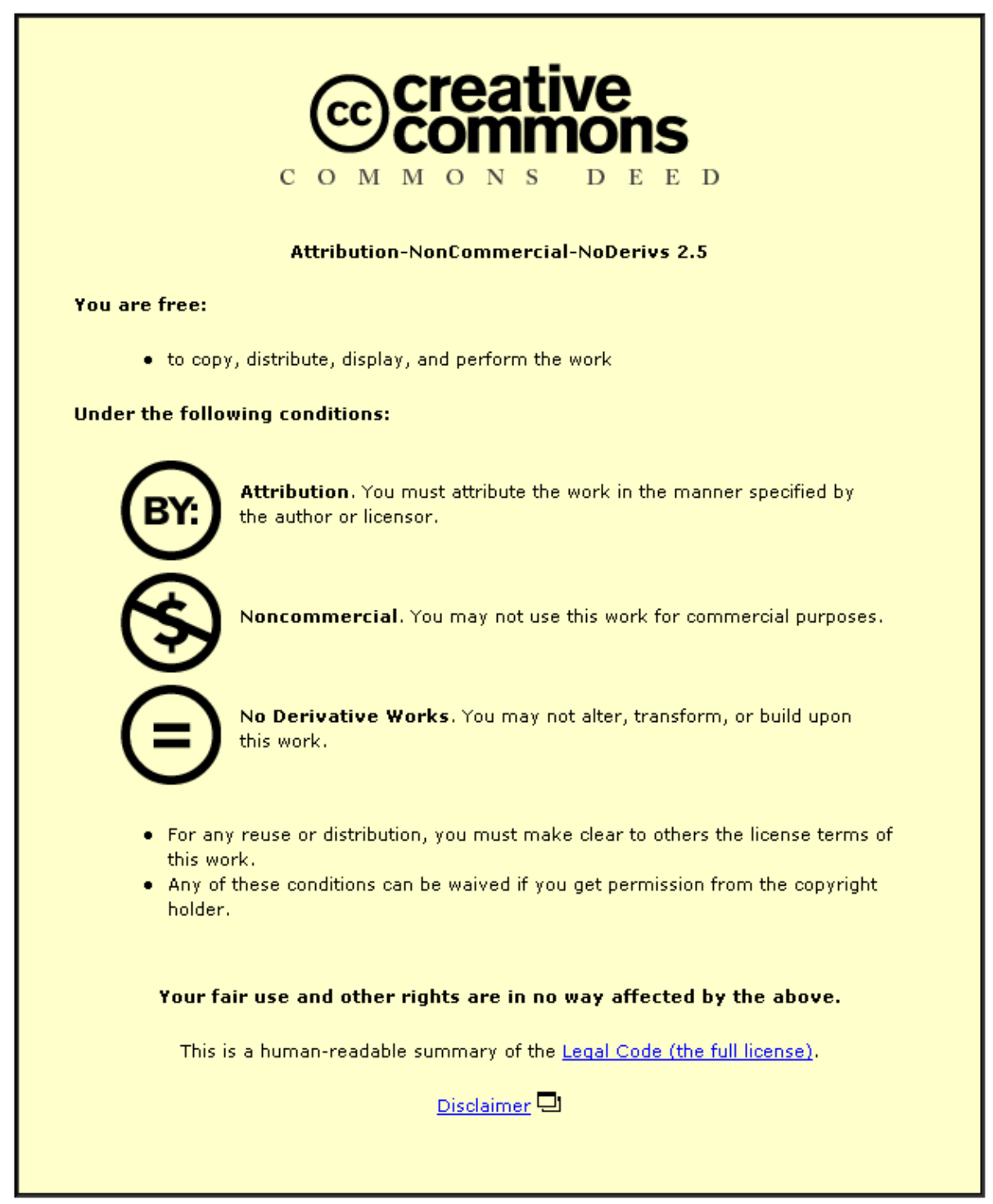

For the full text of this licence, please go to: http://creativecommons.org/licenses/by-nc-nd/2.5/ 


\title{
A Statistical Summary of Mall-Based Stair-Climbing Interventions
}

\section{Oliver J. Webb, Frank F. Eves, and Jacqueline Kerr}

\begin{abstract}
Background: Stair climbing is an accessible activity with proven health benefits. This article summarizes the effectiveness of mall-based stair-climbing interventions, while controlling for, and examining, potential moderators of stair/escalator choice. Methods: Six comparable studies were identified, which used poster/ banner prompts to promote stair choice. Original data were combined and analyzed using logistic regression. Pedestrians' stair/escalator choices $(\mathrm{N}=127,221)$ provided the dichotomous outcome variable. Demographics (eg, gender), condition (baseline vs. intervention), and 'pedestrian traffic volume' were entered as potential moderators. To examine durability of effects, the rate of stair climbing in each half of the intervention period was compared. Results: Overall, stair choice was more common in men (odds ratio $[\mathrm{OR}]=1.72$ ), under-60s $(\mathrm{OR}=1.91)$, Whites $(\mathrm{OR}=1.38)$, those without accompanying children $(\mathrm{OR}=1.53)$, and periods of high traffic $(\mathrm{OR}=1.55)$. The rate of stair climbing increased in the intervention phase relative to baseline $(\mathrm{OR}=$ $2.09)$, with greater effects among women $(\mathrm{OR}=1.99)$ versus men $(\mathrm{OR}=1.86)$, and under-60s $(\mathrm{OR}=2.62)$ versus over-60s $(\mathrm{OR}=1.93)$. Intervention effects fell slightly during the second half of the intervention period $(\mathrm{OR}=0.92)$. Conclusions: Conventional mass media campaigns engage an extra $5.0 \%$ of people in physical activity. The current calculations indicate that comparatively simple poster/banner prompts can increase stair climbing in mall settings by $6.0 \%$.
\end{abstract}

Keywords: physical activity, environment, health promotion

In the US and UK between $52 \%$ and $76 \%$ of adults are insufficiently active. ${ }^{1,2}$ These individuals face increased risk of morbidity and premature death. ${ }^{3}$ Increasing population activity levels is, therefore, important. Efforts to engage individuals in structured exercise have proven problematic. ${ }^{4}$ Evidence now indicates that accumulating activity, throughout the day, can afford similar benefits to 1 sustained session. ${ }^{5}$ Thus, current recommendations call for at least $30 \mathrm{mins} /$ day of moderate intensity activity, which can be accrued in bouts of 10 mins or more. ${ }^{6}$

Although evidence is currently limited, experts recognize that spells of activity lasting less than 10 mins may be beneficial. ${ }^{6}$ One behavior with potential dividends is stair climbing. In a training study by Boreham et al, participants climbed a standardized staircase once per day in week 1 , rising to twice per day in week 2 , and so on. ${ }^{7}$ After 7 weeks, individuals showed improved cholesterol profiles and cardio-vascular fitness, relative to controls. On average, each ascent lasted just 135 secs. The health impact of stair climbing can be traced to its

\footnotetext{
Webb is with the School of Sport, Exercise, and Health Sciences, Loughborough University, Loughborough, United Kingdom. Eves is with the School of Sport and Exercise Sciences, University of Birmingham, Birmingham, United Kingdom. Kerr is with the Dept of Family and Preventive Medicine, University of California, San Diego.
}

vigorous nature. Climbing the stairs expends 9.6METs (ie, 9.6 times the energy used at rest), making it more intensive per minute than 'traditional' forms of exercise such as jogging. ${ }^{8,9}$ Furthermore, because stair climbing involves raising one's weight against gravity, energy expenditure should be greater among overweight individuals. Indeed, cross-sectional data indicate that 'real world' stair climbing may be useful in terms of weight control. In a pan-European study, Shenassa et al observed significantly lower BMI among men who resided on the fourth floor or above, versus first floor dwellers. ${ }^{10}$ These findings coincide with Eves et al's prediction that an $80 \mathrm{~kg}$ man, ascending a $3 \mathrm{~m}$ staircase 10 times per day, would expend $27.5 \mathrm{kcals}$. ${ }^{11}$ Over a year this equates to $10,035 \mathrm{kcal}$, , or around 4 days without food. Alongside these physiological benefits, stair climbing is a freely available indoor activity that does not require special clothing, equipment, or training. Thus, typical barriers to participation do not apply.

Several investigators have examined ways of promoting stair choice. Typically, interventions involve the introduction of message prompts, extolling the virtues of stair climbing, at the 'point-of-choice' between the stairs and the mechanical alternative (ie, the elevator/escalator). To date, there has been no robust attempt to summarize intervention effects statistically.

Dolan et al pooled effect sizes from 8 studies to estimate the impact of a hypothetical city-wide campaign. ${ }^{12}$ 
Unfortunately, the authors omitted several pertinent studies without explanation. ${ }^{13-16}$ Furthermore, the studies which were included used disparate outcome measures. While some recorded stair use (a combined measure of pedestrians' ascending and descending movements), ${ }^{17,18}$ others specifically monitored stair climbing. ${ }^{19,20}$ The overall effect size computed by the authors is, therefore, uninterpretable, as it does not refer to a distinct behavior. Finally, Dolan et al treated studies as homogeneous, despite critical differences in where they were conducted. Some studies were hosted in workplaces, where individuals chose between stairs and an elevator. ${ }^{17,18}$ Other studies were conducted in public-access settings (eg, malls and train stations), where the alternative to the stairs was an escalator. ${ }^{19}$ While escalators remain permanently available for use, individuals must often wait for an elevator to arrive. The associated delay could serve to incentivize stair choice. Indeed, this contextual difference might explain the paradox whereby baseline rates of stair climbing are higher in workplaces, consisting of at least 4 stories, than in shopping malls, which only feature a single flight of stairs..$^{21}$ Significantly, the availability of the elevator(s) is entirely random and could, therefore, serve to dilute the potential effects of workplace interventions. ${ }^{21}$ Clearly, one must differentiate studies by setting when combining or comparing data.

The current article sought to statistically summarize the effects of stair-climbing interventions, while addressing the problems outlined above. An important prerequisite is that studies are only combined if they feature a consistent outcome variable. Where studies report stair use, it is impossible to decipher the respective effects of an intervention on ascending and descending movements. This distinction is critical. Stair climbing expends around twice as many calories as stair descent (9.6 vs. 4.9METs) and is, therefore, the target behavior for health promoters. ${ }^{89}$ Hence, studies which specifically report rates of stair climbing must be prioritized.

In accurately assessing the efficacy of interventions, another requirement is that additional moderators are adequately controlled for. As with other forms of physical activity, individuals' engagement in stair climbing may, for example, be influenced by their demographic characteristics (eg, gender, age, ethnicity). Thus, variation in the study population between conditions could produce changes in stair climbing, which might be falsely attributed to an intervention. Clearly, it is important for investigators to control for competing sources of causality wherever possible. Herein there exists a further problem with combining data from disparate settings. In workplaces and train stations the only demographic variable that investigators have consistently monitored is gender. By contrast, studies in shopping malls have routinely recorded a host of demographic and personal variables (eg, gender, age, ethnicity, level of baggage, presence of accompanying children). Furthermore, there can be differences in how moderators are coded between studies. For example, studies in train stations and shopping malls have both controlled for effects of "pedestrian traffic volume' - that is, the total number of pedestrians using the stairs and escalators at a given time. In malls, traffic has been computed as the number of ascending pedestrians using a stair/escalator pairing in a $30 \mathrm{~min}$ window. ${ }^{13-16,22-24}$ In train stations, however, traffic is 'pulsatile' in nature-the sporadic arrival of services producing extreme peaks and troughs. Consequently, in these venues traffic has been measured as the total number of people alighting from each service. . $^{16,25,26}$ Given these disparate measures, traffic data from the different settings cannot be combined.

In light of the issues above, the current article focuses on mall-based stair-climbing interventions. These constitute the majority of studies in the area. In addition, they are the only studies where investigators have recorded a comprehensive range of potential moderators. Conventional practice would be to conduct a meta-analysis. Put simply, this would involve weighting effects by sample size to produce an average. In an alternative approach, we synthesized original data sets and reanalyzed them. This method provided a definitive estimate of intervention effects, which was corrected for the impact of other moderators. It also allowed us to investigate interactive effects between the interventions and demographic characteristics.

\section{Methods}

\section{Data Preparation}

The lead investigator conducted Metalib searches for relevant papers published between 1970 and 2008. The following keyword combinations were used; 'stair,' 'use,' 'climbing,' and 'intervention.' Articles were considered for inclusion if they involved baseline and intervention conditions and took place in a mall setting. Nine articles were found, containing a total of 12 independent studies. ${ }^{13-16,22-24,27,28}$ All were written in English. Reference lists from the articles were scrutinized for additional publications and authors were e-mailed to inquire about unpublished data sets. No additional data were obtained.

The 12 studies were scrutinized for methodological consistency. Consequently, several were excluded; one for reporting stair use; ${ }^{27}$ one for failing to record pedestrians' age, ${ }^{16} 2$ for failing to record pedestrians' ethnicity; ${ }^{16,28}$ and one because the experimental site deviated from the prototypical format of a central staircase flanked by escalators. ${ }^{23}$ Evidence suggests that poster prompts less than 'A1' size $(594 \mathrm{~mm} \times 841 \mathrm{~mm})$ are suboptimal. Thus, a final study was rejected for using 'A2' posters $(420 \mathrm{~mm}$ $\times 594 \mathrm{~mm}) .{ }^{16}$

The 6 remaining studies exclusively used message prompts to encourage stair choice. They did not feature additional incentives, nor did they form part of any larger physical activity campaign. Each study followed a quasi-experimental interrupted time-series design, whereby pedestrians' ascending stair/escalator choices were observed by trained personnel during baseline and a subsequent intervention phase (see Table 1). The studies 
were good quality, featuring substantial sample sizes and interobserver reliability rates of between $94 \%$ and $100 \%$ for the demographic variables. Three studies employed conventional A 1 posters, ${ }^{13,28}$ and 3 used banners attached to the stair-risers themselves. ${ }^{15,22,24}$ Across the studies, potential moderators were consistently coded as follows; 'gender' (male/female); 'ethnicity' (White/Non-White); 'age' ( \pm 60 years, as determined by the presence of gray hair and/or wrinkles); 'baggage' (anything larger than a briefcase or medium-sized bag); 'accompanying children' (those below adult waist height); and 'pedestrian traffic volume' (number of individuals ascending the stairs and escalators every 30 mins). All of the studies excluded pushchair/wheel chair users and unaccompanied youths (those between adult waist and shoulder height).

Original data were recovered. Each data set was separately assessed to establish the stability of effects over the lifespan of the intervention phase. For all data sets, week-by-week analyses revealed no significant increase or decline in the rate of stair climbing over the course of the interventions. In other words, the effects of the interventions were stable, irrespective of how long they lasted. Thus, the differing lengths of the 6 interventions did not represent a confounding factor.

Pedestrian traffic levels were liable to differ between study sites, however. To allow analyses of traffic that were not confounded by these site-specific differences, traffic values were adjusted. The following 3 stage process was performed on each of the 6 data sets in turn. First, traffic values in the data set were checked for outliers. Consequently, a total of 2605 observations were excluded across the 6 data sets. Next, all of the traffic values in the data set were divided by the highest value. This converted the values such that they now lay within a range spanning from 0 to 1 . Finally, these new traffic values were mean centered. The benefit of this process was that it retained the variability in traffic values data at each site, while removing the gross differences in traffic values between sites. ${ }^{25}$ Data from all 6 studies were now collapsed to form a composite data set. Any follow-up observations, collected postintervention, were removed.

\section{Data Analysis}

The composite data set was analyzed using logistic regression (SPSS 16.0). Stair/escalator choice served as the dichotomous outcome variable. The moderators from above were entered into the model, along with 'condition' (baseline vs. intervention). Interaction terms between moderators were progressively tested. Previous research indicates differences in the effectiveness of conventional poster prompts and stair-riser banners. ${ }^{16}$

Table 1 Descriptives of the Studies in the Composite Data Set

\begin{tabular}{|c|c|c|c|c|c|}
\hline Author & $\begin{array}{l}\text { Sample } \\
\text { size after } \\
\text { exclusions }\end{array}$ & Setting & Format & Design & Message(s) used \\
\hline Kerr et $\mathrm{a}^{28}$ & 6969 & UK mall & A1 posters & $\begin{array}{l}2 \text { weeks baseline } \rightarrow 2 \\
\text { weeks intervention }\end{array}$ & "Stay healthy, use the stairs" \\
\hline Kerr et al ${ }^{13}$ & 24,895 & UK mall & A1 posters & $\begin{array}{l}2 \text { weeks baseline } \rightarrow 14 \\
\text { weeks intervention }\end{array}$ & "Stay healthy, use the stairs" \\
\hline Kerr et al ${ }^{13}$ & 7030 & UK mall & A1 posters & $\begin{array}{l}2 \text { weeks baseline } \rightarrow 2 \\
\text { weeks posters } \rightarrow 2 \text { weeks } \\
\text { banners }^{\mathrm{a}}\end{array}$ & "Stay healthy, use the stairs" \\
\hline Kerr et al ${ }^{15}$ & 31,566 & UK mall & $\begin{array}{l}\text { Stair-riser } \\
\text { banners }\end{array}$ & $\begin{array}{l}2 \text { weeks baseline } \rightarrow 13 \\
\text { weeks intervention }\end{array}$ & $\begin{array}{l}\text { "Take the stairs," "Keep fit," "Daily exercise," } \\
\text { "Work your legs," "Free exercise," "Stay healthy," } \\
\text { "Easy exercise,","Be active," "Exercise your } \\
\text { heart," "Well done!" }\end{array}$ \\
\hline $\begin{array}{l}\text { Webb \& } \\
\text { Eves }^{22}\end{array}$ & 29,673 & UK mall & $\begin{array}{l}\text { Stair-riser } \\
\text { banners }\end{array}$ & $\begin{array}{l}2 \text { weeks baseline } \rightarrow 4 \\
\text { weeks intervention }\end{array}$ & $\begin{array}{l}\text { "Take the stairs," "Keep fit," "Daily exercise," } \\
\text { "Work your legs," "Free exercise," "Stay healthy," } \\
\text { "Easy exercise,","Be active," "Exercise your } \\
\text { heart," "Well done!" }\end{array}$ \\
\hline $\begin{array}{l}\text { Webb \& } \\
\text { Eves }^{24}\end{array}$ & 27,088 & UK mall & $\begin{array}{l}\text { Stair-riser } \\
\text { banners }\end{array}$ & $\begin{array}{l}2 \text { weeks baseline } \rightarrow 13 \\
\text { weeks intervention }^{\mathrm{b}}\end{array}$ & $\begin{array}{l}\text { "Take the stairs," "Stair climbing burns more } \\
\text { calories per minute than jogging," "Stair climb- } \\
\text { ing burns more calories per minute than tennis," } \\
\text { "7 minutes of stair climbing per day protects your } \\
\text { heart" }\end{array}$ \\
\hline
\end{tabular}

\footnotetext{
${ }^{a}$ Data from the banner phase of the intervention was excluded.
}

${ }^{\text {b }}$ Data from the 'generalization' site was excluded. 
Thus, separate analyses were also conducted for each intervention format.

\section{Sample Size Calculations}

To verify that the analysis of the composite data set was sufficiently powered, retrospective calculations were conducted using PASS (version 08.0.07). ${ }^{29}$ For each moderator in the model, PASS computed the minimum sample size required to produce the corresponding OR with power $=0.80$ and alpha $=.05$. Crucially, PASS accounts for the presence of the other moderators during these calculations.

\section{Analysis of Durability}

Three studies involved medium-term interventions of 13 to 14 weeks. ${ }^{13,15,24}$ To test the durability of effects a modified data set was created, comprising data from the intervention phase of these studies $(\mathrm{N}=67,062)$. A new variable- 'intervention segment'-distinguished between weeks 1 to 7 ('first segment') and weeks 8 to 14 ('second segment') of the intervention phase. A supplementary regression was performed on this data set, including 'intervention segment' alongside the moderators from above.

\section{Results}

The composite data set contained 127,221 stair/escalator choices (mean traffic $=310$ persons $/ 30$ mins; range $=112-586)$. Of the population observed, $57.6 \%$ were female, $77.8 \%$ were under- $60,82.3 \%$ were classified as White, $1.7 \%$ had accompanying children, and $10.1 \%$ were carrying baggage. At baseline, $5.5 \%$ of individuals climbed the stairs. The fourth column in Table 2 shows the minimum sample size required for each moderator. The composite data set satisfied these values.

Table 2 also shows the logistic regression results. Crucially, there was a main effect of 'condition.' The baseline rate of stair climbing was multiplied by this OR to determine the rate of stair climbing produced by the interventions, having corrected for the effects of all other moderators. This rate is plotted in Figure 1. As can be seen, the level of stair climbing is substantially higher in the intervention phase relative to baseline.

There was a main effect of 'gender' such that men climbed the stairs more overall than women. An interaction between 'condition' and 'gender' also suggested differential responding to the interventions between sexes. Thus, separate analyses were conducted for each gender. The interventions were associated with larger effects among women $(\mathrm{OR}=1.994$; $\mathrm{CIs}=1.639-2.426$; $P<.001)$ versus men $(\mathrm{OR}=1.860 ; \mathrm{CIs}=1.547-2.236$; $P<.001)$. As before, these ORs were used to plot stairclimbing rates which are corrected for all other moderators (Figure 1). As can be seen, during the intervention phase women showed a proportionately greater increase in stair climbing.

There was also a significant main effect of 'Age,' with overall rates of stair climbing higher among the under-60s. In addition, a significant interaction between 'intervention' and 'age' was observed. Separate analyses for each age group show that the over-60s $(\mathrm{OR}=1.930$; CIs $=1.687-2.207 ; P<.001)$ increased their level of stair climbing less during the intervention phase than their younger counterparts $(\mathrm{OR}=2.617$; $\mathrm{CIs}=2.413-2.837$; $P<.001$ ) (Figure 1).

There were significant effects of 'ethnicity' and 'accompanying children,' such that White individuals and

Table 2 Results of Logistic Regression Analyses and Sample Size Calculations for Moderators of Stair Climbing

\begin{tabular}{|c|c|c|c|c|c|c|c|}
\hline \multirow[b]{3}{*}{ Moderator } & & & & \multicolumn{4}{|c|}{ Separate analyses by intervention format } \\
\hline & \multicolumn{3}{|c|}{$\begin{array}{l}\text { Analysis of the full composite data set } \\
\qquad(N=127,221)\end{array}$} & \multicolumn{2}{|c|}{$\begin{array}{c}\text { Stair-riser banner } \\
\text { interventions }(\mathrm{n}=\mathbf{8 8 , 3 2 7 )}\end{array}$} & \multicolumn{2}{|c|}{$\begin{array}{c}\text { Conventional poster } \\
\text { interventions }(n=38,894)\end{array}$} \\
\hline & OR & $95 \%$ Cls & $\begin{array}{l}\text { Sample required } \\
\text { to test the effect }\end{array}$ & OR & $95 \%$ Cls & OR & $95 \%$ Cls \\
\hline Intervention vs. baseline & $2.086^{*}$ & $1.801-2.416$ & 2420 & $2.585^{*}$ & $2.375-2.815$ & $1.739 *$ & $1.538-1.967$ \\
\hline Male vs. female & $1.719^{*}$ & $1.563-1.890$ & 2101 & $1.608 *$ & $1.445-1.789$ & $1.949^{*}$ & $1.763-2.154$ \\
\hline Under-60 vs. over- 60 & $1.914 *$ & $1.676-2.187$ & 2651 & $2.193 *$ & $2.068-2.326$ & $2.896^{*}$ & $2.480-3.381$ \\
\hline White vs. non-White & $1.377^{*}$ & $1.309-1.448$ & 10,610 & $1.686^{*}$ & $1.599-1.778$ & $1.186 * * *$ & $0.985-1.427$ \\
\hline $\begin{array}{l}\text { No accompanying children } \\
\text { vs. accompanying children }\end{array}$ & $1.534 *$ & $1.305-1.802$ & 65,735 & $1.380 * *$ & $1.158-1.646$ & $1.904 * *$ & $1.216-2.980$ \\
\hline Pedestrian traffic volume & $1.554 *$ & $1.366-1.769$ & 300 & $1.231 * *$ & $1.072-1.412$ & $2.259^{*}$ & $1.541-3.312$ \\
\hline No baggage vs. baggage & $0.981 * * *$ & $0.921-1.046$ & - & $1.115^{* *}$ & $1.043-1.193$ & $1.217 * * *$ & $0.974-1.520$ \\
\hline Condition $\mathrm{x}$ gender & $0.865^{* *}$ & $0.781-0.959$ & - & $0.830 * *$ & $0.740-0.931$ & \multicolumn{2}{|c|}{ no interaction } \\
\hline Condition $\mathrm{x}$ age & $1.243^{* *}$ & $1.075-1.437$ & - & \multicolumn{2}{|c|}{ no interaction } & \multicolumn{2}{|c|}{ no interaction } \\
\hline
\end{tabular}

Abbreviations: OR, odds ratio; CI, confidence interval.

$* P<0.001$.

$* * P<0.01$.

*** $P>0.05$. 


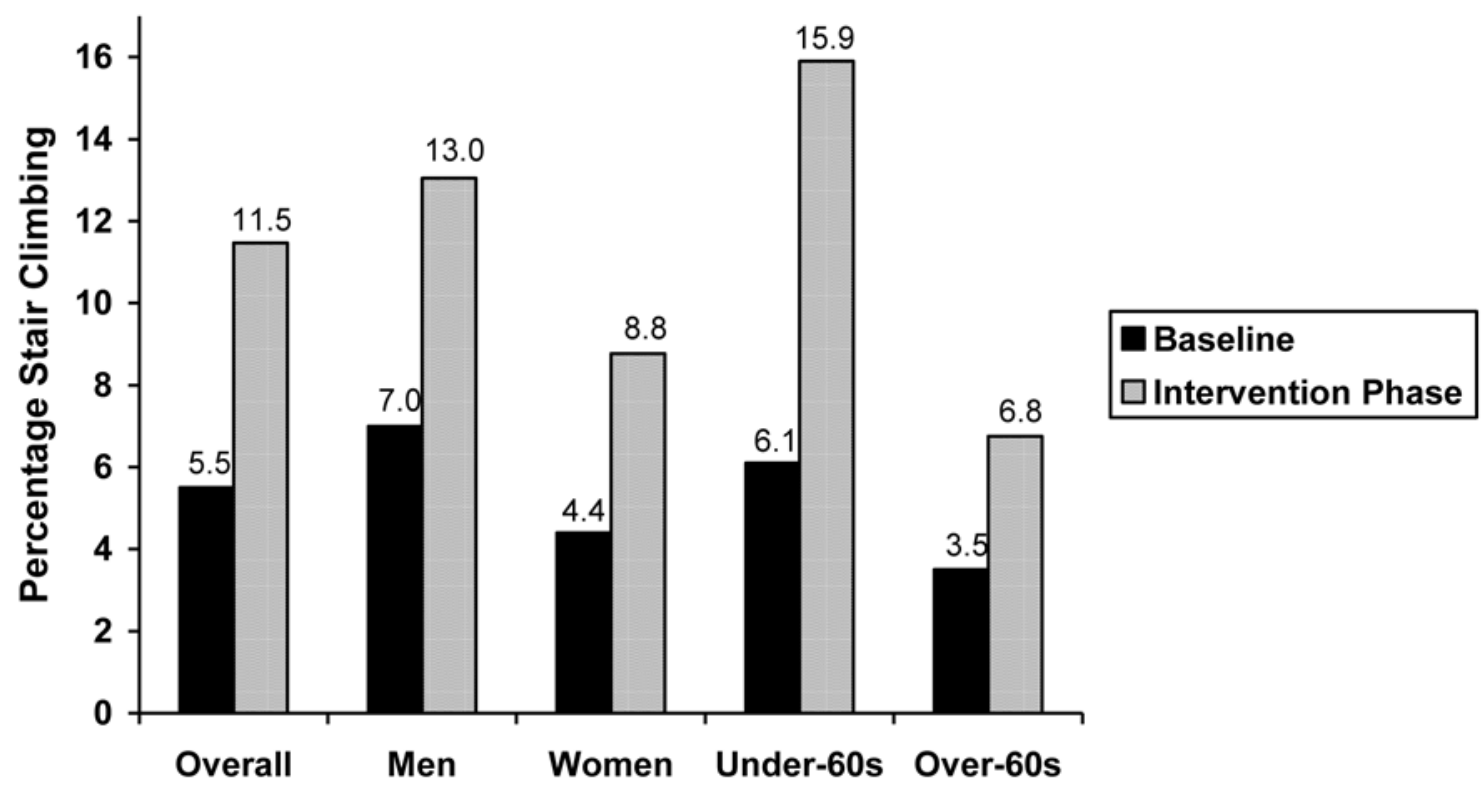

Figure 1 - Corrected rates of stair climbing during baseline and intervention conditions, stratified by gender and age.

those without children climbed the stairs more, overall, than their counterparts. These moderators did not, however, interact with the intervention phase. A main effect of 'pedestrian traffic volume' was also observed. As traffic levels increased, so did the proportion of people who took the stairs. 'Baggage' was the only variable which was not related to stair climbing. There were no significant 3-way interactions.

The supplementary analysis confirmed that the rate of stair climbing in the second segment of the intervention phase $(11.4 \%)$ was significantly lower than in the first segment $(12.5 \%)(\mathrm{OR}=0.924$; CIs $=0.873-0.977$; $P<.01)$. Meanwhile, the separate analyses show that although both formats were associated with increased levels of stair climbing, a more sizeable OR was observed for banner interventions than conventional posters (Table 2). Broadly speaking, the analysis of the full data set, and the separate analyses performed for banner interventions and poster interventions, all showed similar effects for the other moderators. In the separate analyses, however, the 'condition' $\mathrm{x}$ 'age' interaction was not observed. In addition, in the analysis of poster interventions the effect of 'ethnicity' and the 'condition' $\mathrm{x}$ 'gender' interaction did not reach significance. Finally, the analysis of banner interventions found that individuals without baggage were more likely to take the stairs, whereas the analysis of poster interventions found no significant effect of baggage.

\section{Discussion}

The current findings confirm that mall-based interventions are effective. Message prompts more than doubled the rate of stair climbing. In real terms, this meant that an extra $6.0 \%$ of individuals climbed the stairs. Given the volume of pedestrians that are exposed to mall-based interventions, they can be considered a form of mass media delivery. The effects compare favorably with conventional television and print campaigns, which are reported to engage an additional $5.0 \%$ of the population in physical activity over the short-term. ${ }^{30}$ Furthermore, traditional media campaigns rely on retrospective questionnaires for evaluation, which bring problems associated with self-report (eg, socially desirable responding). By contrast, the effects of stair-climbing interventions are directly audited in the field, lending integrity to the results. Moreover, effects do not appear to be limited to already active individuals. Kerr et al interviewed a subsample of stair climbers about their global activity levels. ${ }^{28}$ Those questioned during the intervention reported less activity in the previous 14 days than those interviewed at baseline, indicating that the message prompts had attracted proportionately more sedentary individuals onto the stairs.

When the 6 data sets were separately scrutinized, there was no apparent increase or decline in the rate of stair climbing over the course of the interventions. When data from the 3 medium length interventions was combined, however, the supplementary analysis identified a significant fall in the rate of stair climbing between weeks 1 to 7 and weeks 8 to 14 of the intervention phase. The magnitude of this decline was, however, small $(-1.1 \%)$. Thus, the effects of the interventions were largely sustained over a 3 month period. Further research is clearly needed to establish the durability of intervention effects over the longer term. Importantly, recent findings show that effects 'generalize' beyond the initial point of exposure. ${ }^{23,24}$ When Webb and Eves introduced message banners at 1 point-of-choice, stair climbing increased 
elsewhere in the experimental venue, where no prompts were in place. Thus, an intervention at a single staircase appears to produce a greater accumulation of stair climbing than initially realized. Meanwhile, the simplicity of the materials involved in these interventions dictates that costs are likely to be minimal. Until the magnitude of generalization effects is established, however, cost-benefit analyses would be premature.

As discussed in the introduction, data collected in contextually different settings should not be indiscriminately combined. It is perfectly acceptable, however, to compare effect sizes between venues. On average, Eves et al found that interventions hosted in train stations encouraged an extra $6.6 \%$ of pedestrians to climb the stairs. ${ }^{25}$ These effects correspond with the current findings for mall-based interventions. Importantly, public-access interventions appear to be almost universally successful. To date, 24 of 26 studies which have measured stair use or stair climbing report positive effects on behavior. ${ }^{11,21}$ By contrast, worksite studies have produced equivocal results. ${ }^{21}$ Two studies by Kerr et al found that poster prompts significantly increased stair descent but had no impact on stair climbing. ${ }^{31}$ Meanwhile, some interventions have actually been associated with a decrease in stair choice. ${ }^{32}$ An individual may form intentions to take the stairs as a consequence of a workplace intervention. If, on approaching the point-of-choice, the elevator is free, however, he/she may be tempted inside because it offers a faster means of ascent. The availability of elevators is completely random across individuals and conditions and could, therefore, serve to dilute intervention effects. ${ }^{21}$ Nevertheless, workplace interventions should not be dismissed out-of-hand. Eves et al employed a message which described specific health benefits of stair climbing and the amount required to attain these ("Doctors have found that 7 minutes of stair climbing a day halves your risk of a heart attack over a 10 year period. There are 1440 minutes in a day. Can you spare 7 minutes to live longer ... ?"). ${ }^{33}$ Interview work indicates that this approach is more likely to motivate stair choice than generic entreaties to be active (eg, "Regular stair climbing helps to keep you active"). ${ }^{34}$ Eves et al's intervention persuaded an extra $2.5 \%$ of 'normal weight' individuals to climb the stairs. Importantly, the effects were more pronounced among people coded as overweight - an extra $5.4 \%$ of these individuals climbing the stairs during the intervention. Adults are estimated to spend half their waking hours in the workplace ${ }^{35}$ Thus, one must balance the impressive efficacy of public-access interventions against the fact that workplaces offer more opportunity for repeated contact with individuals. There is a clear challenge for health promoters to optimize the efficacy of interventions in all settings by applying principles of best practice.

In terms of intervention format, the current findings corroborate existing evidence that stair-riser banners are more effective than posters in malls. ${ }^{13}$ Heightened visibility appears to explain this superiority; previous studies report recall rates of $78 \%$ for banners, vs. 37\% for posters. ${ }^{14,28}$ One should be cautious, however, in translating this finding to other settings. A recent train station study found opposite results—-stair-riser banners were ineffectual, while posters significantly increased stair climbing. ${ }^{26}$ The authors reasoned that traffic levels can become so extreme in commuter venues as to completely obscure the stair-risers. It is clearly important to consider the idiosyncrasies of settings when planning interventions.

Turning to the potential moderators of stair climbing, a significant relationship between pedestrian traffic volume and behavior emerged. As traffic levels increased so did levels of stair climbing. There is a plausible explanation for this phenomenon. During busy periods escalators can become saturated with bodies. Faced with the prospect of queuing to use the escalator, individuals may take the stairs to expedite their journey.

In terms of demographic characteristics, the over-60s climbed the stairs less overall than their younger counterparts. One reason may be that this group stand at heightened risk of articular complaints (eg, arthritis), which could make stair climbing uncomfortable. ${ }^{36}$ An interaction between 'intervention' and 'age' also indicated that the over-60s were less responsive to point-of-choice prompts. Given that stair climbing may not be viable for some over-60s on health grounds, the smaller effects may simply reflect the reduced population pool from which to recruit stair climbers. Nonetheless, it is encouraging that significant effects were observed among this group. The relationship between stair climbing and ethnicity is less explicable. Non-Whites climbed the stair less overall than Whites. While there are well-documented associations between cultural beliefs and participation in physical activity, this is unlikely to offer a complete explanation. In the current data set many of the Non-White individuals were younger, and hence likely to be acculturated to Western views. Furthermore, it is doubtful that the relationship between ethnicity and stair/escalator choice is wholly driven by a confounding factor, such as weight. Brownell et al recorded a host of demographic variables in their seminal intervention, adjusting the effect of each moderator for all other factors. ${ }^{19}$ Ethnicity and weight status were found to have independent negative effects on stair choice. Qualitative research may be useful in unraveling ethnicity effects. It is, however, encouraging that the interventions had homogenous effects among Whites and Non-Whites.

Overall, women climbed the stairs less than men. Differences in clothing do not appear to explain this disparity. Stair/escalator choice is not related to heel height, for example (Kerr et al, unpublished). Physiological differences offer an alternative explanation. Women have an average muscle power-to-weight ratio of $2.7 \mathrm{watts} / \mathrm{kg}$, compared with $4.0 \mathrm{watts} / \mathrm{kg}$ among men. ${ }^{37}$ Objectively speaking, women are, therefore, likely to find stair climbing more exerting than men. Again qualitative research may be useful in explaining gender differences. Encouragingly, analyses indicated that women were more responsive to the interventions. On first glance this finding is exciting from a public health perspective. Stair climbing protects against conditions which are most prevalent in women (eg, osteoporosis and reduced muscle strength). ${ }^{38,39}$ Careful interpretation of the figures is, 
however, essential. During the intervention phase women did indeed show a greater increase in stair climbing proportionate to their baseline levels. In real terms, however, this increase was still smaller than observed among men $(+4.4 \%$ vs. $+6.0 \%$, see Figure 1$)$. Thus, the heightened responding observed among females appears, in part, to be driven by low rates of baseline stair climbing.

The analysis of the composite data set found no significant impact of baggage on rates of stair climbing. The separate analyses performed for each intervention format produced differing results, however. The analysis of poster interventions found no significant effect of baggage. Conversely, the analysis of stair-riser banner interventions found a small effect of baggage, such than unladen individuals were more likely to take the stairs. Issues of statistical power may be relevant here. Relative to the banner venues, fewer pedestrians at the poster sites had baggage ( $7.2 \%$ vs. $11.5 \%)$. Thus, the analysis of poster interventions had less power to detect a significant effect of baggage. When all data were combined, the low number of laden pedestrians at the poster sites could also have diluted the power of the composite model to detect significant effects of baggage on behavior.

It is extremely significant that across the 3 analyses, all of the other moderators assessed were related to stair climbing. The findings validate the decision to omit data sets which did not include these variables. Wherever moderators of stair climbing are not controlled for, there is a real chance of misleading results. For example, in a mall setting Webb et al. (in preparation) found that pedestrian traffic volume was around $10 \%$ higher during school vacations compared with term time. According to the current findings, this rise in traffic would increase stair climbing at the site. Consequently, were the intervention phase of a study to coincide with a school vacation, the effects would be falsely exaggerated. Conversely, if the baseline phase coincided with a school vacation, the true impact of the intervention would be obscured. Phenomena such as school vacations can further confound findings, by altering the demographic profile of the study population. During a school vacation, there would likely be more young people using the venue, which would again impact on levels of stair climbing.

In addition to recording potential moderators of stair climbing, prospective investigators should ensure that they achieve adequate sample sizes. Issues of power and sample size are seldom discussed in stair-climbing papers. According to the current findings, however, sizeable samples are required to study the effects of relatively rare phenomena (eg, accompanying children). Where possible, investigators are encouraged to estimate the necessary sample size a priori. Differences in statistical power could explain why the 'condition' $x$ 'age' interaction which appeared in the composite data set was not observed during the separate analyses for each format type.

It is important to consider the strengths and limitations of the current study. Given the size of the composite data set, the current findings can be generalized to the general population. It must be recognized, however, that they are only applicable to stair-climbing behavior in mall settings. Furthermore, it should be noted that of the 12 studies which were initially identified, 6 were omitted due to methodological inconsistencies. These exclusions highlight the pressing need for investigators to adopt consistent methods and measures. To be specific, studies should explicitly measure stair climbing, and record a comprehensive host of moderator variables using consistent coding criteria. Only then can the isolated studies be galvanized to provide a coherent evidence base.

There are likely to be additional moderators which influence stair/escalator choice. For example, 2 methodologically-robust studies have demonstrated effects of weight status on stair climbing. ${ }^{19,33}$ In addition, the physical characteristics of the setting may be important. A recent audit of university faculty buildings identified 10 spatial variables which influenced stair use (eg, stair width) ${ }^{40}$ In conjunction, 3 variables accounted for $53 \%$ of the variance in behavior. Finally, the content of the messages used in interventions represents a potential source of variance. As mentioned, the 'specificity' of messages may moderate the effectiveness of interventions. ${ }^{34}$ It might be possible to isolate other message characteristics which can be exploited to optimize intervention effects. Overall, the onus is on prospective researchers to broaden the scope of potential moderators that they measure.

The current analyses provide compelling evidence that simple mall-based interventions achieve sizeable changes in stair climbing, which endure into the medium term. This article also quantifies the substantial impact that demographic and contextual factors have on behavior, and demonstrates the importance of adopting consistent methods to help advance knowledge in this domain.

\section{References}

1. Department of Health. Health Survey England 2003. The risk factors for Cardiovascular Disease. Vol 2. London: Stationery Office; 2004.

2. Macera CA, Ham SA, Yore MM, et al. Prevalence of physical activity in the United States: Behavioral Risk Factor Surveillance System, 2001. Prev Chronic Dis. 2005;2:A17.

3. US Department of Health and Human Services. 2008 physical activity guidelines for Americans. Washington, DC: US Department of Health and Human Services; 2008.

4. Marshall AL. Challenges and opportunities for promoting physical activity in the workplace. J Sci Med Sport. 2004;7:60-66.

5. Hardman AE. Issues of fractionalization of exercise (short vs long bouts). Med Sci Sports Exerc. 2001;33:S421-S427.

6. Pate RR, Pratt M, Blair SN, et al. Physical activity and public health. A recommendation from the Centers for Disease Control and Prevention and the American College of Sports Medicine. JAMA. 1995;273:402-407.

7. Boreham CAG, Wallace WFM, Neville A. Training effects of accumulated daily stair-climbing exercise in previously sedentary young women. Prev Med. 2000;30:277-281.

8. Ainsworth BE, Haskell WL, Whitt MC. Compendium of physical activities: an update of activity codes and MET intensities. Med Sci Sports Exerc. 2000;32:S498-S516. 
9. Teh KC, Aziz AR. Heart rate, oxygen uptake, and energy cost of ascending and descending the stairs. Med Sci Sports Exerc. 2002;34:695-699.

10. Shenassa ED, Frye M, Braubach M, Daskalakis C. Routine stair climbing in place of residence and Body Mass Index: a pan-European population based study. Int J Obes. 2008;32:490-494.

11. Eves FF, Masters RSW, McManus A, Leung M, Wong P, White MJ. Contextual barriers to lifestyle physical activity interventions in Hong Kong. Med Sci Sports Exerc. 2008;40:965-971.

12. Dolan MS, Weiss LA, Lewis RA, Pietrobelli A, Heo M, Faith MS. 'Take the stairs instead of the escalator': effects of environmental prompts on community stair use and implications for a national 'Small Steps' campaign. Obes Rev. 2006;7:25-32.

13. Kerr J, Eves FF, Carroll D. Encouraging stair use: stairriser banners are better than posters. Am J Public Health. 2001;91:1192-1193.

14. Kerr J, Eves FF, Carroll D. Getting more people on the stairs: the impact of a new message format. J Health Psychol. 2001;6:495-500.

15. Kerr J, Eves FF, Carroll D. Six-month observational study of prompted stair climbing. Prev Med. 2001;33:422-427.

16. Kerr J, Eves FF, Carroll D. The influence of poster prompts on stair use: the effects of setting, poster size and content. Br J Health Psychol. 2001;6:397-405.

17. Boutelle KN, Jeffery RW, Murray DM, Schmitz M. Using signs, artwork, and music to promote stair use in a public building. Am J Public Health. 2001;91:2004-2006.

18. Kerr NA, Yore MM, Ham SA, Dietz WH. Increasing stair use in a worksite through environmental changes. $\mathrm{Am} \mathrm{J}$ Health Promot. 2004;18:312-315.

19. Brownell KD, Stunkard AJ, Albaum JM. Evaluation and modification of exercise patterns in the natural environment. Am J Psychiatry. 1980;137:1540-1545.

20. Marshall AL, Bauman AE, Patch C, Wilson J, Chen J. Can motivational signs prompt increases in incidental physical activity in an Australian health-care facility? Health Educ Res. 2002;17:743-749.

21. Eves FF, Webb OJ. Worksite interventions to promote stair climbing; reasons for caution. Prev Med. 2006;43:4-7.

22. Webb OJ, Eves FF. Promoting stair use: single versus multiple stair-riser messages. Am J Public Health. 2005;95:543-1544.

23. Webb OJ, Eves FF. Effects of environmental changes in a stair climbing intervention: generalization to stair descent. Am J Health Promot. 2007;22:38-44.

24. Webb OJ, Eves FF. Promoting stair climbing: intervention effects generalize to a subsequent stair ascent. Am J Health Promot. 2007;22:114-119.
25. Eves FF, Olander EK, Nicoll G, Puig-Ribera A, Griffin C. Increasing stair climbing in a train station; effects of contextual variables and visibility. J Environ Psychol. 2008;3:232-249.

26. Olander EK, Eves FF, Puig-Ribera A. Promoting stair climbing: stair-riser banners are better than posters... sometimes. Prev Med. 2008;47:308-310.

27. Andersen RE, Franckowiak SC, Snyder J, Barlett SJ, Fontaine KR. Can inexpensive signs encourage the use of stairs? Results from a community intervention. Ann Intern Med. 1998;129:363-369.

28. Kerr J, Eves F, Carroll D. Posters can prompt less active people to use the stairs. J Epidemiol Community Health. 2000;54:942-943.

29. Hintze J. PASS 2008. Kaysville, UT: NCSS, LLC; 2008. www.ncss.com

30. Snyder LB, Hamilton M, Mitchell EW, Kiwanuka-Tongo J, Fleming-Milici F, Proctor D. A meta-analysis of the effect of mediated health communication campaigns on behavior change in the United States. J Health Commun. 2004;9:71-96.

31. Kerr J, Eves FF, Carroll D. Can posters prompt stair use in a worksite environment? J Occup Health. 2001;43:205-227.

32. Coleman KJ, Gonzalez EC. Promoting stair use in a US-Mexico border community. Am J Public Health. 2001;91:2007-2009.

33. Eves FF, Webb OJ, Mutrie N. A workplace intervention to promote stair climbing: greater effects in the overweight. Obesity (Silver Spring). 2006;14:2210-2216.

34. Webb OJ, Eves FF. Promoting stair climbing: effects of message specificity and validation. Health Educ Res. 2007;22:49-57.

35. Dishman RK, Oldenburg B, O'Neal H, et al. Worksite physical activity interventions. Am J Prev Med. 1998;15:344-361.

36. Watkins KW, Shifren K, Park DC, Morrell RW. Age, pain, and coping with rheumatoid arthritis. Pain. 1999;82:217228.

37. Sports Council and Health Education Authority. Allied Dunbar national fitness survey. London: Sports Council and Health Education Authority; 1992.

38. Coupland CA, Cliffe SJ, Bassey EJ, Grainge MJ, Hosking DJ, Chilvers CED. Habitual physical activity and bone mineral density in postmenopausal women in England. Int J Epidemiol. 1999;28:241-246.

39. Loy SF, Conley LM, Sacco ER, et al. Effects of stairclimbing on VO2max and quadriceps strength in middle-aged females. Med Sci Sports Exerc. 1994;26:241-247.

40. Nicoll G. Spatial measures associated with stair use. Am J Health Promot. 2007;21:346-352. 